\title{
WHAT IS EPISTEMIC PUBLIC TRUST IN SCIENCE?
}

\author{
Gürol Irzik and Faik Kurtulmus
}

Forthcoming in BJPS

\begin{abstract}
We provide an analysis of the public's having warranted epistemic trust in science, that is, the conditions under which the public may be said to have well-placed trust in the scientists as providers of information. We distinguish between basic and enhanced epistemic trust in science and provide necessary conditions for both. We then present the controversy regarding the (alleged) connection between autism and measles-mumpsrubella vaccination as a case study to illustrate our analysis. The realization of warranted epistemic public trust in science requires various societal conditions, which we briefly introduce in the concluding section.
\end{abstract}

\section{Introduction}

2. Basic Epistemic Trust in Science

3. Deciding Whom to Trust

4. Enhanced Epistemic Trust in Science

5. A Case Study: The Alleged Causal Link Between MMR Vaccination and Autism

5.1 A brief overview of the $M M R$ controversy: the scientific perspective

5.2 The public's perspective

5.3 Enhanced epistemic trust in the MMR controversy

\section{Conclusion}

\section{Introduction}

Epistemic public trust in science is essential for both the individual and the common good. We routinely rely on the findings of science for personal and public health from the use of antibiotics to the drinking of tap water. We abide by the decisions of the criminal courts that involve the science of forensics. Moreover, the very existence of much of scientific research depends on citizens' tacit or explicit consent to the public funding of science through taxes. None of this would be the case if people were distrustful of scientists. However, what is socially desirable in this context is not mere 
trust, but rather warranted trust, that is, people investing trust in trustworthy scientists with good reasons. Nevertheless, what it means for the public to have warranted epistemic trust in scientists has not been studied sufficiently in the philosophical literature.

Accordingly, our aim in this article is to provide the conditions necessary for the public to invest warranted epistemic trust in scientists as providers of information. ${ }^{1}$ By warranted epistemic trust we mean well-placed epistemic trust: trust with good grounds invested in those scientists with the required qualities for being trustworthy. Thus, we shall be concerned not with a socio-psychological account of why the public actually trusts or distrusts scientists, but rather with warranted public trust as a normative notion, spelling out success conditions for the trust relationship. We find it useful to distinguish between two kinds of trust: basic and enhanced epistemic trust in science. We devote sections 2 and 3 to an analysis of the former. Wilholt ([2013]) presents a penetrating analysis of epistemic trust within science in terms of an enhanced kind of epistemic reliance. He argues that if the scientific community is to do justice to the epistemic trust invested in them from outside of science, it is not enough that scientists observe the methodological standards of their trade; they sometimes also need to take into account people's expectations about the distribution of inductive risks an important condition that we utilize in our analysis. We have constructed the phrase 'enhanced epistemic trust in science' out of Wilholt's 'epistemic trust as an enhanced kind of epistemic reliance' and built his requirement regarding public's expectations about the distribution of inductive risks into our analysis of it, which we offer in section 4 . In section 5 we present the controversy regarding the (alleged) connection between autism and the measles-mumps-rubella vaccination as a case study to illustrate our analysis and argue that enhanced trust may be difficult to achieve when collective and individual interests are not aligned. Our discussion reveals that the realization of warranted epistemic public trust in science requires various societal conditions, which we briefly introduce in the concluding section.

\footnotetext{
${ }^{1}$ Throughout this paper, when we speak of public trust in science, we actually speak of public trust in scientists, not the institution of science in general. Furthermore, we are presupposing that the public has a certain level of trust in science as a whole as a way of obtaining knowledge about the world.
} 


\section{Basic Epistemic Trust in Science}

Since epistemic trust is a kind of trust, it would be useful to begin with some key features of trust in general. Trust is a three-place relationship between the truster, the trustee, and the object of trust: A person trusts another with something, which can be an action, a state of affairs, or a proposition (Baier [1986], Hardin [2002]). In the case of epistemic trust for our purposes in this article, the object of trust is a proposition or a set of propositions $\mathrm{P}$.

Baier characterizes trust as a special kind of reliance: it is reliance on another's good will. Karen Jones adds that 'trust is an attitude of optimism that the good will and competence of another will extend to cover the domain of our interaction with her, together with the expectation that the trusted will be directly and favourably moved by the thought that we are counting on her' (Jones [1996], p. 19). When I trust my friend with something, I rely on her good will and competence and leave it to her discretion to look after it. Yet there is no guarantee that she will do so. Hence, trust involves risk-taking and makes the truster vulnerable (Baier [1986], [1995]). Thus, unlike mere reliance which can only be disappointed, trust can be betrayed and give rise to reactive attitudes (Holton [1994], pp. $66-7)$.

We do not just trust anybody with no reason; we invest trust only in those whom we think are trustworthy, that is, those whom we believe to have the required qualities such as good will, competence, experience, sound judgement and so on (Hardwig [1985], [1991], Smolkin [2008]). A number of philosophers employ this connection between trust and trustworthiness for clarifying the nature of epistemic trust. For example, in his influential account of the role of trust in knowledge, John Hardwig ([1985], [1991]) maintains that A comes to know that P based on B's testimony when B knows that $\mathrm{P}$ and speaks truthfully, and $\mathrm{A}$ has good reasons to believe that both conditions are fulfilled. Thus, our knowledge based on testimony depends greatly on the epistemic and moral character of our sources. Ben Almassi links epistemic trust with trustworthiness as follows: 'I trust your testimony that $\mathrm{P}$ to the degree that $\mathrm{I}$ regard you as competent in your acceptance of $\mathrm{P}$ and conscientious in your presentation of testimony that $\mathrm{P}$, and so I take your testimony that $\mathrm{P}$ as providing evidence of (a contributing reason to believe) P' (Almassi [2012], p. 43). On the other hand, McCraw proposes the following account of epistemic trust: A person $\mathrm{H}$ places 
epistemic trust in another person $\mathrm{S}$ that $\mathrm{P}$ if and only if '(1) $\mathrm{H}$ believes that $\mathrm{P}$, (2) $\mathrm{H}$ takes $\mathrm{S}$ to communicate that $\mathrm{P}$, (3) $\mathrm{H}$ depends upon $\mathrm{S}$ 's (perceived) communication for H's belief that $\mathrm{P}$, and (4) $\mathrm{H}$ sees $\mathrm{S}$ as epistemically wellplaced with respect to P' (McCraw [2015], p. 425), where the phrase 'epistemically well-placed' is used to indicate S's having epistemic authority and competence. ${ }^{2}$ Hardwig, Almassi and McGraw all draw out the distinctive features of epistemic trust that we, for the most part, preserve in our account. Epistemic trust is about taking someone's testimony that $\mathrm{P}$ as a reason to believe that $\mathrm{P}$ on the assumption that she is in a position to know whether $\mathrm{P}$ and will express her belief truthfully.

Let $\mathrm{M}$ be a member of the public investing warranted trust in scientists $(\mathrm{S})$ as providers of information, which is a proposition or a set of propositions (P). S can be an individual scientist or a collective body composed of scientists who are organized in a way that enables them to jointly assert that $\mathrm{P}$. To begin with, for $\mathrm{M}$ to trust $\mathrm{S}$ as a provider of information that $\mathrm{P}, \mathrm{P}$ must be communicated to $\mathrm{M}$ by $\mathrm{S}$. Scientists may directly disseminate $\mathrm{P}$ themselves, say by appearing on TV, or more commonly by publishing an article in a scientific journal. Alternatively, their belief that $\mathrm{P}$ may be reported indirectly by the media. Either way, scientists have the responsibility to state $\mathrm{P}$ as accurately and as wholly as possible, and, when they directly address the public, to report it in light of the public's informational needs and capacities. If $\mathrm{M}$ later finds out that crucial information has been suppressed or withheld from her, her trust would be betrayed.

When $\mathrm{M}$ trusts $\mathrm{S}$ that $\mathrm{P}, \mathrm{M}$ takes $\mathrm{S}$ 's statement that $\mathrm{P}$ as a strong but defeasible reason to believe that $\mathrm{P} .{ }^{3}$ While $\mathrm{M}$ can have other reasons to believe that $\mathrm{P}, \mathrm{S}$ 's communication of $\mathrm{P}$ must be a distinct reason for $\mathrm{M}$ to believe that $P$ if we are to speak of a relation of trust between $M$ and $S$. If $M$ believes that $\mathrm{P}$, but $\mathrm{S}$ 's communication of $\mathrm{P}$ is not one of the grounds of M's belief, then we cannot speak of $\mathrm{M}$ placing epistemic trust in S. Moreover,

${ }^{2}$ However, McCraw's first condition is too strong. While the testimony of someone in whom we place epistemic trust gives us a reason to believe them, this reason can be defeated by other reasons that we have. Suppose you have a condition that a doctor diagnoses as lupus, but a second doctor disagrees. Both doctors, let us assume, are competent and speak truthfully. In such a case, you may rationally withhold judgement. According to McCraw's account, you don't have epistemic trust in either doctor. It is, however, more natural to claim that you have epistemic trust in both doctors, and it is the fact that their claims contradict each other that leads you to withhold judgement.

3For purposes of simplicity, we treat belief as an all or nothing matter, setting aside degrees of belief. 
what is a reason for $\mathrm{M}$ to believe that $\mathrm{P}$ has to be not only that $\mathrm{S}$ believes that $\mathrm{P}$ but also the fact that $\mathrm{S}$ communicates that $\mathrm{P}$. Epistemic trust involves reliance on the good will of the person trusted and the expectation that they will be truthful. When $\mathrm{M}$ believes something merely because $\mathrm{S}$ believes it, this does not entail that $\mathrm{M}$ trusts $\mathrm{S}$. Suppose a dictator is afraid of being poisoned by his aide. He drinks the water his aide offers him only if his aide drinks water from the same source. Even though the dictator believes that the water is safe because his aide believes so, this does not mean he trusts him. Similarly, when we expect someone to tell the truth only for selfinterested reasons, this does not involve trust. When she misleads us, we would feel disappointed but not betrayed. In the case of scientists, the requirement of good will for epistemic trust amounts to their commitment to the ethical norms of their trade and their sense of obligation to truthfully and accurately share significant knowledge with the public. ${ }^{4}$

Trust, as we have seen, involves reliance not only on the good will but also on the competence of the person trusted. What would this amount to in the case of epistemic trust in $\mathrm{S}$ ? A natural thought is that the information $\mathrm{P}$ provided by $\mathrm{S}$ must be true. This, however, would make warranted public trust practically impossible because the information $\mathrm{S}$ convey is based on their research, and scientific research cannot guarantee truth since it is fallible. Yet when conducted well, scientific research does produce information that is likely to be true. This suggests the requirement that $\mathrm{P}$ be produced by $\mathrm{S}$ in a reliable way even though P's being produced reliably does not guarantee its truth. More specifically, following Alvin Goldman's reliabilism in epistemology (Goldman [1986]), we will say that a piece of scientific research that yields $\mathrm{P}$ is reliable if it is carried out according to methodological guidelines (i.e., methods, procedures, rules and standards communally endorsed and monitored) that make the objective probability of $\mathrm{P}^{\prime}$ s being true sufficiently high. For if a piece of scientific research is not reliable and yet $\mathrm{M}$ is convinced of scientists' trustworthiness, say, due to empty rhetoric or sheer propaganda, then her trust would not be warranted. Moreover, because unreliable research seldom produces truths, its applications and policies based on it would tend to fail M's expectations for beneficial output. In short, reliability is essential for warranted public trust.

Even the requirement of actual reliability may seem too demanding. Imagine someone who has misleading evidence suggesting that a particular

\footnotetext{
${ }^{4}$ For a helpful discussion of the relationship between trust and norms of knowledge sharing see Grasswick ([2010]).
} 
piece of research is reliable even though it isn't and relies on it. Can this person be said to have warranted epistemic trust? On our account the answer is 'no' since the research in question was unreliable, and we think this is as it should be. Warranted epistemic trust is well-placed trust, and someone can misplace their trust without being at fault. Yet, it is not enough that research producing $\mathrm{P}$ should be reliable. $\mathrm{M}$ should also have good reasons to believe that $\mathrm{P}$ is the output of reliable research. In the absence of such a constraint, M's warranted epistemic trust in science becomes largely a matter of luck.

In both of these respects warranted trust is analogous to knowledge on the traditional analysis. Just as in order for a belief to count as knowledge it has to be both (at least) justified and true, warranted epistemic trust requires that it be based on good reasons and that its object be actually trustworthy.

Pulling these together, we offer the following analysis. $M$ has warranted epistemic trust in $\mathrm{S}$ as a provider of $\mathrm{P}$ only if (1) $\mathrm{S}$ believes that $\mathrm{P}$ and honestly (i.e. truthfully, accurately and wholly) communicates it to $\mathrm{M}$ either directly or indirectly ${ }^{5}$, (2) $\mathrm{M}$ takes the fact that $\mathrm{S}$ believes and has communicated that $\mathrm{P}$ to be a (strong but defeasible) reason to believe that $\mathrm{P}$, (3) P is the output of reliable scientific research carried out by S, and (4) M relies on $\mathrm{S}$ because she has good reasons to believe that $\mathrm{P}$ is the output of such research and that $\mathrm{S}$ has communicated $\mathrm{P}$ honestly. While (1) and (3) spell out the necessary conditions for $\mathrm{S}$ to be trustworthy, (2) and (4) specify the necessary conditions for $\mathrm{M}$ to trust $\mathrm{S}$ and do so with good reasons.

Once we have this analysis at our disposal, public epistemic trust can be formulated as follows: the relevant public will be said to invest warranted epistemic trust in $\mathrm{S}$ as a provider of $\mathrm{P}$ when a sufficient number of its members invest warranted epistemic trust in $\mathrm{S}$ as a provider of $\mathrm{P} .{ }^{6}$ Our formulation refers to the relevant public, because the boundaries of "the

5In the case of a collective body of scientists and the group's belief that $\mathrm{P}$, our account is neutral between summative accounts, which maintain that a group has a belief that $\mathrm{P}$ only if all or most of its members believe that $\mathrm{P}$, and non-summative accounts that reject this requirement. For a discussion, see (Gilbert [1987]).

6This is not the only sense in which the expression 'public trust in science' can be employed. It may also be used to refer to the trust that public bodies acting on behalf of the public have in scientists. For instance, if an institutional body such as the Department of Health invests trust in scientists, that may also be referred to as public trust in science. Public trust in scientists in that sense may not be reducible to the trust that individuals within such bodies have. While we think public trust in scientists in that sense is also important, our account is not intended to capture it. 
public' are determined contextually and usually left implicit. Often it is meant to include all adults living in a certain country, but it can also include smaller or larger groups of people. Moreover, the public is not a homogenous entity and different groups may have different expectations from scientific research (Resnik 2011).

The four conditions above constitute the necessary requirements for what we call 'public's warranted basic epistemic trust in S'. As we shall see in section 4 , it is possible to specify further conditions the satisfaction of which will enhance public's epistemic trust in $\mathrm{S}$.

It should be obvious from our account that the public's having warranted epistemic trust in $\mathrm{S}$ is a matter of degree. This is because, first, the degree of trust $\mathrm{M}$ ought to have in $\mathrm{S}$ that $\mathrm{P}$ depends on the reliability of S's research; the more reliable $\mathrm{S}$ 's research is, the higher the trust $\mathrm{M}$ ought to place in $\mathrm{S}$. Second, the stronger reasons $M$ has regarding S's honesty and the reliability of her research, the more warrant she will have for investing a particular degree of trust in $\mathrm{S}$. Thus, the degree of trust $\mathrm{M}$ places in $\mathrm{S}$ is well-placed to the extent that it matches the strength of reasons $M$ has for believing $S$ to be honest and S's research to be reliable.

Warranted epistemic trust in science then distributes different burdens on different actors and institutions. For instance, conditions 1 and 3 require that scientists produce $\mathrm{P}$ reliably and honestly disseminate it through an appropriate venue. Since the public's access to $\mathrm{P}$ is typically through the media, the media has the important responsibility of disseminating $\mathrm{P}$ properly. Therefore, it plays a crucial role in bringing about warranted trust. Condition 4, on the other hand, places a burden on the public. For even if a particular piece of research is reliable, the public rarely has direct first-order reasons for believing that this is indeed the case. Can they have any justification for thinking that the information scientists have provided them with is the output of reliable research and therefore likely to be true? We address this question in the next section.

\section{Deciding Whom to Trust}

Expertise comes in degrees and is domain specific (Collins and Evans [2007]). For this reason, there may be situations and domains in which even lay people can claim to have some expertise and have access to first-order 
reasons for judging reliability. ${ }^{7}$ However, in many cases they will not be in a position to understand or evaluate first-order reasons for deciding whether a particular piece of research is reliable. In such cases the public can instead judge the scientists themselves in terms of criteria which could function as second-order reasons. Here we shall follow the work by Alvin Goldman (Goldman [2001]) and especially Elizabeth Anderson (Anderson [2011]), who usefully categorizes the criteria in question into four groups: assessing expertise, honesty, epistemic responsibility, and the existence of a consensus of trustworthy experts.

Anderson points out that scientists who have a high degree of expertise, who are honest and epistemically responsible are more trustworthy than those who lack such qualities. Criteria for judging scientific expertise reflect the hierarchy of expertise from holding a B.S. degree to holding a $\mathrm{PhD}$. degree in the field of inquiry, all the way up to being a scientist whose research is widely recognized by other scientists in the field and to being a leader in the field, indicated by such factors as being elected to national academies and receiving prizes for scientific achievements. The public should give more weight to the testimony of those higher in the ladder of hierarchy. Criteria for assessing honesty, on the other hand, include the absence or presence of conflicts of interest; evidence of previous misconduct such as plagiarism, fabricating, distorting or suppressing crucial data; misrepresenting the claims of other scientists, and the like. Criteria for judging epistemic responsibility include whether the research has been published in a peer-reviewed scientific journal, whether the researcher refuses to share data for no good reason, and whether s/he fails to acknowledge or engage with refutations of one's own claims, etc. Finally, the public can decide whether a consensus has been consolidated about a certain conclusion by inspecting surveys of the peer-reviewed literature and of trustworthy experts, and above all by checking if such bodies as National Science Academies around the world have issued any consensus reports. ${ }^{8}$ Obviously, none of these criteria are conclusive reasons for trusting or distrusting scientists. Rather they are reasons that should figure in lay persons' deliberations in deciding to what degree to trust a scientist.

\footnotetext{
${ }^{7}$ In fact, the failure of scientists to acknowledge the expertise of lay people can undermine the relationship of trust. For a discussion see Whyte and Crease ([2010]).

8See Oreskes ([2007]) and Anderson ([2011]) for helpful examples of how lay people can indeed make sound second-order judgements of scientists' trustworthiness about an issue as complex as the anthropogenic global warming.
} 
Many of these criteria, in particular the criteria for assessing honesty and epistemic responsibility, apply directly to groups of scientists as well. For instance, one can assess whether a research collaborative has conflicts of interest or whether it engages with criticisms of its work. Moreover, even if it is conceded that the beliefs and testimony of a group cannot be reduced to the beliefs and testimony of its individual members, as has recently been argued by Tollefsen ([2007]) and Wilholt ([2016]), it is still the case that the reliability and honesty of individual members have a bearing on the trustworthiness of the group's testimony. Thus, considerations of whom to trust that operate only at the individual level can help decide whether to trust groups. Tollefsen and Wilholt give two reasons for the irreducibility of a group's reliability to the testimony of its individual members. First, they rightly note that in many cases of group testimony there is a division of labour and different individuals are responsible for different parts of the statement. This, however, does not entail that the trustworthiness of individual members of the group does not impact the reliability of the group's testimony. If one part of a joint statement is due to a single member, then its reliability is influenced by that person. Second, they point out that when individual beliefs are aggregated through certain procedures, the reliability of the group's belief may be higher than the reliability of each individual's belief as demonstrated in Condorcet's Jury Theorem and the performance of prediction markets. This is of course true, but these results still are, at least in part, shaped by facts about individuals. If, for instance, people do not express their beliefs with honesty or the probability that they will have a correct belief regarding a proposition is less than chance, then Condorcet's Jury Theorem is not applicable. Accordingly, information about the trustworthiness of individual scientists that constitute the group who give testimony can inform us about the group's trustworthiness even though this information will not be conclusive.

Finally, we should also note that since the public is not a homogenous entity, some groups, unlike others, may have legitimate reasons not to trust certain scientists due to their differing social positions and past experiences. For instance, in light of the history of the Tuskegee experiments, African Americans may be justified in distrusting the medical community and therefore in demanding more evidence of the good will and honesty of a scientist or the reliability of her research than others who do not share the same history (Grasswick [2010], Scheman [2001]). Our account easily captures this. The fact that the doctors who carried out the Tuskegee experiments misled their subjects, thereby failing to satisfy condition (1), 
means that conditions (2) and (4) are much more difficult to satisfy for African Americans.

\section{Enhanced Epistemic Trust in Science}

In section 2 we offered an analysis of what we have called 'the public's warranted basic epistemic trust in science', which included the condition that the research that yields $\mathrm{P}$ must be reliable in the sense that the objective probability of its output being true is sufficiently high. This requirement leads to a further condition. ${ }^{9}$ How high should the probability of P's being true be in order for scientists $(\mathrm{S})$ to decide to accept $\mathrm{P}$ and communicate it to the public? That decision is typically made on the basis of communally endorsed methodological guidelines about the significance level in statistical testing, when to discard certain data or decide that all the likely sources of 'noise' have been eliminated, and the like. However, in certain cases in which the public welfare is at stake, it may be desirable that the methodological guidelines scientists employ for accepting or rejecting $\mathrm{P}$ take into account inductive risks, that is, $\mathrm{P}$ 's consequences in relation to two types of error - false positives and false negatives. ${ }^{10}$ False positives arise when one accepts a hypothesis as true even though it is not, and false negatives arise when one rejects it as false even though it is not. Suppose now that either one has serious consequences for $\mathrm{M}$. If $\mathrm{S}$ take their expectations into account when making methodological decisions, and moreover if those members have reason to believe that $S$ have done so, then they would certainly invest further (over and above basic) trust in $\mathrm{S}$.

Hence, we propose to add two further conditions to our earlier analysis: (5) When public welfare is at stake, in making methodological decisions regarding the distribution of inductive risks with respect to $\mathrm{P}, \mathrm{S}$ make those decisions in agreement with the M's assessments of the inductive risks in question, and (6) $\mathrm{M}$ has reason to believe that Condition 5 is satisfied. Basic epistemic trust plus these two conditions yield what we call 'public's (warranted) enhanced epistemic trust in science'.

The difference between basic epistemic trust and enhanced epistemic trust can be illustrated by the following example. Suppose you have two TA's

9The discussion in this paragraph and the Condition 5 it yields are indebted to Wilholt ([2013]).

10For a useful discussion of inductive risks and their significance in hypothesis acceptance and science policy, see Douglas ([2000] and [2009]). 
whom you trust: you rely on their good will, truthfulness, ethical integrity and competence. They proctor exams in two separate classrooms and both report to you that they each have caught a student cheating on the exam. You are particularly worried about falsely charging a student with cheating. You know that the first TA has the same concern, whereas the second TA is more concerned with not letting any student get away with cheating. While you have basic epistemic trust in both TA's, you have enhanced epistemic trust in the first TA who shares your concern. Their reports will have different force in your deliberations and you will be much more inclined to take action based on the first TA's report. Enhanced trust will make an even more significant difference in the case of the public's reliance on scientists, where they are not in a position to judge the first-order evidence bearing on the claims in question.

One might object to our distinction between basic and enhanced epistemic trust on the grounds that the former is mere epistemic reliance and does not deserve to be called 'epistemic trust'. Consider, for example, Wilholt's account of epistemic trust within science. Wilholt claims that when a scientist relies on the results of her fellow scientists on the assumption that they were obtained by proper employment of the methodological standards of the pertinent relevant community, that is mere epistemic reliance - unless it is coupled with the requirement that scientists broadly agree on the value judgements regarding the evaluations of inductive risks their methodological decisions involve (Wilholt [2013], p. 248). Taking his cue from Wilholt's argument, our objector might similarly claim that Condition 3, even when taken in conjunction with Condition 4, does not amount to epistemic trust - unless combined with Condition 5, which requires that the public's and scientists' value judgements about the distribution of inductive risks more or less coincide in certain cases.

There are several reasons why we think that such a conclusion must be resisted. First, according to our analysis, $\mathrm{M}$ has reason to believe that $\mathrm{P}$ because $\mathrm{S}$ not only believes that $\mathrm{P}$ but also has communicated to $\mathrm{M}$ that $\mathrm{P}$ in an honest way. $\mathrm{M}$ is thus dependent on the goodwill, truthfulness and ethical integrity of $\mathrm{S}$ with respect to $\mathrm{P}$. This dependence, it seems to us, goes beyond mere epistemic reliance and constitutes a basic form of epistemic trust. While science indeed has mechanisms that punish dishonesty, they cannot by themselves ensure that scientists always act honestly. Thus, our expectation that scientists will be honest is based not on the conviction that honesty is what best serves their self-interest but on the 
conviction that they adhere to the ethical norms of science (Hardwig [1991], pp. 702-706).

Second, in many cases of fundamental research such as theoretical work concerning star formation in cosmology and unified field theory in physics, false negatives and false positives are highly unlikely to have any impact on public welfare, in which case there is no reason to require that scientists should take into account people's expectations about inductive risks (assuming they have any expectations), nor to demand that the expectations of the two groups match. But then according to our objector in such cases we cannot speak of epistemic public trust at all - which is counter-intuitive.

Finally, if we accept our objector's reasoning, then epistemic public trust in science becomes impossible when the public's and scientists' value judgements about the distribution of inductive risks diverge. We provide a case study of such divergence in section 5. More worrisome for our objector's position are cases where the public, unlike the scientific community, has a biased or erroneous assessment of the inductive risks, because, for instance, they disregard certain populations or long-term consequences. In such cases, our objector would have to say that scientists are untrustworthy. ${ }^{11}$ We can make much better sense of such cases by saying that while there is basic epistemic trust there is not enhanced epistemic trust between scientists and the public.

Enhanced epistemic trust makes a much more direct kind of reliance on scientists possible for the public. It also provides the public with an added level of assurance. When conditions 5 and 6 are satisfied, the public knows that scientists have taken measures to avoid the kind of possible errors that the public would like to avoid. Indeed, in applied research in such fields as medicine, pharmacology, genetic engineering and toxicology that could bring both immense benefits and catastrophic harm to people, it may be desirable that scientists take into account people's expectations about the distribution of inductive risks when making methodological decisions. ${ }^{12} \mathrm{We}$ can assume that scientists can do that without sacrificing scientific rigour. Condition 6, however, places a heavy burden on the shoulders of ordinary citizens. How can they discharge it? As with condition 4, they are typically

11We thank Martin Carrier for this point.

12 Note that we do not take a position on whether scientists should always take the public's evaluation of inductive risks into account. Our claim is conditional: If scientists have taken the public's evaluation into account and the public has good reasons to believe that this is the case, then the public can have warranted enhanced epistemic trust in scientists. 
in no position to have first-order reasons as to whether Condition 5 is satisfied or not for any research finding. Perhaps then they can appeal to second-order reasons discussed in section 3? Unfortunately, those reasons typically function as a proxy for whether a given piece of research is reliable or not, not for whether its inductive risks are distributed in a way to meet public's expectations. However, we believe there are two mechanisms that can introduce the public's views on inductive risks to scientific research. Their existence can give the public reasons to believe that Condition 5 is satisfied.

Hybrid forums: Consider hybrid forums (in the form of consensus conferences, citizens' juries and panels practiced in many countries), where a group of scientists and a small number of ordinary citizens, representative of all segments of their society, come together for a few days or even weeks to deliberate upon a specific scientific issue that concerns the public. ${ }^{13}$ During these meetings the citizens raise whatever questions and concerns they have, and the scientists respond to them. ${ }^{14}$ It is at this stage, we suggest, the citizens can also inquire about whether there are any serious inductive risks involved for their welfare and if so what they are, share their expectations about them and explore whether they match the value judgements of scientists. If the deliberative process results in an agreement between their respective value judgements, this will no doubt enhance the representative citizens' trust in the scientists. Provided the media does a good job of disseminating the conclusions reached to the rest of the citizens, then the public too will have increased enhanced trust in scientists.

Diversity: Feminist philosophers of science have long argued that the diversity of deeply held values and diversity with respect to gender, ethnicity and class of researchers contribute to scientific objectivity by eliminating or limiting their prejudices (see, for example, Keller [1985] and Longino [1990]). To the extent individuals' prejudices bias scientific conclusions, such diversity can be said to enhance the reliability of research. It seems to us that diversity in the intended sense can also serve as a kind of secondorder reason we are looking for in Condition 6. That is, it can be argued that the more diverse the group of scientists, the more likely it is that their research will reflect the public's expectations regarding the distribution of inductive risks rather than just a segment of the public. However, it should

13 For an overview of hybrid forums see Bucchi ([2009]). For their role in risk assessment see Douglas ([2009], ch. 8).

14Note that enhanced trust builds upon basic trust, which we assume to be in place in this discussion. 
be acknowledged that even if the scientific community is sufficiently diverse, their values might differ from the public's due to their public responsibilities and their scientific training which inculcates in them a specific set of values (Douglas [2009] pp. 172-173).

Of these two mechanisms, clearly hybrid forums constitute a much more direct and powerful mechanism that enables citizens to introduce their expectations and to see if the inductive risks are distributed to meet them. At any rate, both mechanisms, even though not entirely sufficient, can inform members of the public whether they ought to invest enhanced trust. Finally, it should be noted that high levels of enhanced epistemic trust will be difficult to maintain if there is a lot of variation among the members of the public regarding their evaluations of inductive risks.

\section{A Case Study: The Alleged Causal Link Between MMR Vaccination and Autism.}

The controversy over the alleged link between the measles-mumps-rubella (MMR) vaccine and autism as it unfolded in the UK provides a good case to illustrate our account. We present this controversy first from the scientific research perspective (section 5.1) and then look at it from the public's perspective (section 5.2). Specifically, we ask whether members of the public were in a position to decide in whom to place basic and enhanced epistemic trust in light of the information available to them. As the issue of enhanced epistemic trust is more complex, we take it up in section 5.3.

\subsection{A brief overview of the MMR controversy: the scientific perspective}

In 1998, Andrew Wakefield, a gastroenterologist at the Royal Free Hospital, and his co-authors published a study in The Lancet. The study, based on twelve patients who had been referred to the hospital, suggested that the MMR vaccine was a precipitating cause of a new syndrome of inflammatory bowel disease (enterocolitis) which in turn caused regressive autism (Wakefield et al. [1998]).

In addition to being a case-series with just twelve patients, which is of limited evidential value, the study had various shortcomings that were pointed out in Chen and DeStefano's article that accompanied Wakefield et al.'s article (Chen and DeStefano [1998]). They noted that Wakefield did not report finding vaccine viruses in the bowel or brain tissues of the 
patients involved in the study. They also noted two sources of bias. There could be selection bias in the study since it was known that the group was interested in the connection between inflammatory bowel disease and the MMR vaccine. The MMR vaccine was widely administered in the UK. Thus, just by chance there would be children with both autism and bowel problems who had been vaccinated even in the absence of a causal connection between them. Given that Wakefield was working in a specialist clinic where such cases would be referred to, they were likely to come across patients with this set of symptoms. Chen and DeStefano also pointed out that there could also be recall bias on the parts of parents, given the difficulty of precisely knowing when the symptoms of autism first appeared. Furthermore, they noted that the time when developmental abnormalities first emerge in children with autism is also the time when vaccines are administered. This, they suggested, could lead to false attributions of a causal link.

Immediately following Wakefield's claims, The Medical Research Council (MRC), the government agency in the UK responsible for funding and advancing medical research as well as informing the public about it, had set up an ad hoc committee which consisted of 37 experts from a variety of fields. The MRC concluded that there was 'no evidence to indicate any link between MMR vaccination and bowel disease or autism', and hence no reason to change the existing MMR vaccination policy (Bignall [1998], p. 966). The MRC had also set up an expert subgroup to look further into the research on the link between autism and the MMR vaccine. That group had thirteen members, including virologists, epidemiologists, neuroscientists, and observers from the department of health. The subgroup also invited other specialists, including Wakefield, to particular meetings. The resulting report noted that 'the case for 'autistic enterocolitis' had not been proven' as the studies had been performed in a self-selected and atypical group of patients and that there were alternative explanations of the symptoms that Wakefield and his co-authors had identified that were not ruled out in their study (Fitzpatrick [2004], p. 105).

In 2001 the MRC subgroup's report was followed by a much more thorough MRC report that looked more broadly at the epidemiology and causes of autism. The report, which aimed to inform both health professionals and the general public, was made publicly available on the MRC's website. Since it aimed to address the public's worries as well as informing them, it incorporated 'questions and other extensive input from lay people ... from the outset' (MRC [2001], p. 2). The report also 
summarized several epidemiological studies from the UK, the US and Finland and concluded that 'the current epidemiological evidence does not support the proposed link of MMR to ASDs [autism spectrum disorder]' (MRC [2001], p. 31).

Whereas the first two MRC reports had provided little information that laypeople could use in deciding whether to trust the scientists who had contributed to these reports, the 2001 report provided very detailed information. It included the criteria for membership in the review, steps taken to manage conflicts of interest, and the credentials of the members of the review as well possible sources of conflict (MRC [2001], pp. 68-76).

In March 2004, 10 of the 12 co-authors of the infamous 1998 paper withdrew support from Wakefield's MMR-autism link claim. In February 2010, The Lancet retracted the paper. In the end, Wakefield's integrity as a scientist was put into question. It was found that Wakefield manipulated the data obtained from his twelve patients and failed to disclose his multiple conflicts of interest to the editor of The Lancet. These included his involvement in a patent application of a new vaccine for measles which, he also claimed, would be a treatment for inflammatory bowel disease, as well as receiving substantial sums of money in Legal Aid funding to investigate a possible link between the MMR vaccine and autism to support a class action suit against vaccine manufacturers. As a result, in 2010, a General Medical Council inquiry found Wakefield guilty of 'serious professional misconduct' for having failed to disclose conflicts of interest, acting contrary to the clinical interests of his patients, and misrepresenting facts relevant to his study (GMC [2010]; see also Deere [2011]). Consequently, Wakefield was struck off the medical register, and his 1998 paper was retracted from The Lancet.

In short, already by the end of 2001 the consensus of the relevant medical community was that there was no evidence of causal link between MMR vaccine and autism. By the end of 2010, nothing was left of the alleged causal link, the article that made the claim, and the credibility of its main author.

\subsection{The public's perspective}

Phase 1: Wakefield's public relations strategy - Wakefield had employed a public relations firm (Speers and Lewis [2004], p. 179) - and press coverage played a crucial role in how the controversy over the MMR vaccine unfolded in the UK. The publication of Wakefield's Lancet paper was 
publicized at a press conference in 1998, during which he suggested several times that three single vaccines would be safer than the MMR vaccination in combination - a claim not made in the paper, and rejected by some of his co-authors at the meeting (Boyce [2007], pp. 4-5). The paper and the press conference received limited attention in the media. Thus, the question for our purposes is this: were ordinary people who had been exposed to the news at the time in a position to assess Wakefield's claims? Even though there were first-order reasons to be sceptical of them, it would be too much of a wrench to expect from ordinary citizens to engage with them. More realistically, they were in a position to appeal to second-order reasons, which pointed in the direction of trusting him. He was a doctor in a major teaching hospital. His article was published in The Lancet, one of the most respected medical journals. Although he was a gastroenterologist and not an expert on autism, this was not cause for suspicion given the causal hypothesis he had put forward.

Phase 2: Four years later, in February 2002, the BBC's Panorama, a popular current affairs documentary program, broadcast an episode on Wakefield's claims following the publication of a paper co-written by him that aimed to further support his initial findings. ${ }^{15}$ In the same month, there were measles outbreaks in London and North England. These two events brought Wakefield's claims on the public agenda (Speers and Lewis [2004]). In the period between 1 February and 15 September 2002, there were a total of 285 stories on the link between MMR and autism in the major news outlets in Britain (Boyce [2007], p. 15). Unfortunately, the press did a poor job of informing the public. The convention of seeking to ensure bias-free reporting merely by presenting both sides of a story irrespective of their merits resulted in coverage that gave significant voice to Wakefield's claims. About half the stories in the press gave equal coverage to Wakefield's claims and the consensus in the scientific community against them. Moreover, 32\% of the stories in the press contained only information that was against the MMR vaccine. As a result, the press coverage gave the misleading impression that there was equal support for and against Wakefield's claims (Boyce [2007], pp. 71-94).

15The study published in the journal Molecular Pathology claimed to identify the measles virus in the intestinal tissues of patients with inflammatory bowel syndrome and autism (Uhlman et al. [2002]). However, the study did not establish that the virus was due to the MMR vaccine, and other doubts were raised against the accuracy of its results. Moreover, one of the authors publicly stated that the study was not intended to investigate the role of the MMR vaccine even though that was how Wakefield used the results. For a discussion see (Fitzpatrick [2004], pp. 107-8). 
What and whom to believe regarding the relationship between the MMR vaccine and autism at the height of the media controversy in early 2000's was for many parents an important question. Were they in a position to make an informed decision? The answer is an unequivocal 'yes, with some effort'. For, as we saw in the previous subsection, before the media hype throughout the year 2002, several reports by the British Medical Research Council, one of which specifically targeted the public, were available to them. By presenting the credentials and the institutional affiliations of the committee members, the MRC ([2001]) report provided laypeople with the information they needed for deciding whom to trust. By taking steps to identify and manage conflicts of interest and sharing them with the public, the report assured the public of the integrity of the committee. The report also did a good job of educating the public and placing them in a position to form an opinion about the first-order evidence bearing on the question by outlining the weight of different kinds of evidence, what would be needed to establish a causal link and presenting the existing evidence. Therefore, even at the height of the controversy - before Wakefield's misconduct was revealed and his article retracted - laypeople were in position to place trust on the scientists who maintained that there was no evidence for a connection between the MMR vaccine and autism.

Phase 3: When Wakefield was struck off the medical register and The Lancet retracted his article, it made national news (see, for example, The Guardian, 10 May 2010; see also BBC News 10 May 2010). At that point, ordinary citizens had every possible reason at their disposal not to trust Wakefield and not to believe that MMR vaccine causes autism.

\subsection{Enhanced epistemic trust in the MMR controversy}

The questions raised by enhanced trust are much more complex. The possibilities over which the public's and the scientists' judgements of inductive risks are defined are presented in the table below where $\mathrm{H}$ is the hypothesis 'There is no causal link between the MMR vaccine and autism'16:

\begin{tabular}{|l|l|}
\hline Accept $\mathrm{H} \& \mathrm{H}$ is true & Accept $\mathrm{H} \& \mathrm{H}$ is false \\
\hline Reject $\mathrm{H} \& \mathrm{H}$ is true & Reject $\mathrm{H} \& \mathrm{H}$ is false \\
\hline
\end{tabular}

$16 \mathrm{We}$ are excluding the possibility of suspending judgement for the sake of simplicity and for the reason that the parents have to choose between vaccinating and not vaccinating their children. 
We do not have data to determine how parents and scientists informing the public health officials in the UK ranked these various outcomes. However, a reasonable guess can be made about their respective attitudes towards the possibility of two kinds of error, that is, the bottom left and the top right cells. We believe we can safely assume that scientists' primary concern is public health, whereas parents are primarily concerned with the health of their children. This, we conjecture, can lead to divergences between their respective inductive risk judgements. Arguably, the consequences of rejecting $\mathrm{H}$ when $\mathrm{H}$ is in fact true are much graver from the perspective of scientists than they are from the perspective of parents. First, scientists have to consider not only the harms of mumps, measles, and rubella, but also the costs of allocating resources to treating the increased incidence of these diseases - resources that could otherwise be used to treat other diseases. This is a consideration that does not figure in parents' judgements of risk.

The second reason why parents and scientists may judge inductive risks differently is related to the phenomenon of herd immunity. When a certain rate of vaccination is reached within a population, this contains the risk of contagion, thereby affording protection to those who are not vaccinated. The fact that one may enjoy protection from a disease even when not vaccinated, provided a sufficient number of others are vaccinated, results in risks appearing differently to individual parents and scientists. ${ }^{17}$ If scientists falsely reject $\mathrm{H}$ and announce it to the public, which then leads to a decline in the vaccination rate, they put the whole population at risk of MMR. If, however, a parent falsely rejects $\mathrm{H}$ and acts on this false belief, the risk for their child is relatively small, provided the vaccination rate within the population is high enough and herd immunity obtains. If, on the other hand, they accept $\mathrm{H}$ when $\mathrm{H}$ is in fact false and vaccinate their child, they put their child at risk of autism. Accordingly, the risk involved in falsely rejecting $\mathrm{H}$ is much graver for scientists, who have public responsibilities, than it is for parents.

The considerations we have presented that bear on inductive risk are not conclusive and would need to be corroborated with empirical evidence. Nevertheless, they point to two tentative conclusions. First, parents were in a position to deliberate about whether conditions for enhanced trust were satisfied in the MMR vaccine controversy since the facts we relied on in our discussion were publicly known. Second, it would not be unreasonable for

\footnotetext{
${ }^{17}$ Stephen John ([2011]) also notes how this fact may have shaped the public's thinking about inductive risk.
} 
them to withhold enhanced epistemic trust since scientists had reasons to be more concerned with falsely rejecting $\mathrm{H}$ than parents.

Our discussion suggests that enhanced trust may be difficult to achieve when collective and individual interests are not aligned. Moreover, the lack of enhanced trust between the members of the public and scientists can arise even when people are well informed and scientists have carried out reliable research. In other words, enhanced trust may be lacking even though neither party is at fault when the parties are guided by different values.

\section{Conclusion}

Our analysis reveals that different actors and institutions, who carry out different tasks and engage in different processes, are involved in the building of warranted epistemic public trust in science. These include scientists who are responsible for the production of reliable research and its honest communication. The accurate dissemination of their research to the public is primarily the responsibility of the media, though scientific bodies and journals play an important role in this context as well. Finally, members of the public too must shoulder some responsibility if the epistemic trust they invest in science is to be warranted; that is, they must have good (typically, second-order) reasons for believing that the research results that have been disseminated to them are reliable and that their expectations about the inductive risks involved are satisfactorily met. Let us call this last process 'the process of evaluation'.

Building warranted public epistemic trust in science, then, depends on various institutions' and actors' carrying out their tasks of production, dissemination, and evaluation properly. What are the societal conditions that need to be satisfied to this end? Answering this question requires a study of its own, but we can highlight some of those conditions suggested by our analysis and case study.

Reliability of research findings depends not only on the right employment of appropriate scientific methodology, but also on adherence to the ethical values and norms of science, as seen in the MMR-autism controversy most notably in this case, intellectual honesty and avoidance of financial conflicts of interest. No doubt, violating ethical norms of research - whether they take the form of fabricating data, misrepresenting facts, failing to avoid conflicts of interest or loss of objectivity due to 'funding bias' - can seriously 
undermine the reliability of research. Ultimately, then, reliability of research is a matter of both the proper internal organization of cognitive labour of scientific community (see Kitcher [1993], especially chs. 3 and 8) and the proper social organization of science that includes having the right incentive structure as well as ethical committees that oversees research so that it is not vulnerable to various distorting effects, especially those of financial interests. $^{18}$

Turning to the process of dissemination of scientific information, the media is clearly the most important source for ordinary citizens. For that reason high-quality science journalism emancipated from the profit-maximizing pressures of sensational reporting is a sine-qua-non for public's having access to accurate news about science. Scientific journals too can contribute to the dissemination of scientific findings in a way that is understandable by the public by including lay abstracts - a practice that has been adopted by some medical journals and that should be encouraged in other fields as well. Scientific academies and governmental agencies (like the Medical Research Council in the UK, Surgeon General and the Food and Drug Administration in the USA) also play a crucial role in disseminating scientific information vital for the public. Perhaps the most important institutional precondition for them in view of public trust is their relative autonomy to protect them from the pressures of governments and corporations that could cause biased results.

As for the process of evaluation, obviously people must have the necessary knowledge and skills in order to be able to appeal to the right kind of reasons to form a good opinion about the reliability of research findings disseminated to them. This is of course only possible with a wide and properly functioning basic education system that encompasses all segments of a society. An education that equips people with basic scientific literacy, develops their critical thinking skills and gives them an understanding of how science works in terms of both its methods and social organization (e.g., its system of peer review, its ethical values and norms, etc.) is essential for enabling the public to make judgements regarding whom to trust.

18In fact, people respond to concerns about the incentives scientists face and take them into account when deciding whom to trust. Empirical research suggests that public trust in scientists declines considerably if people think that scientists suffer from financial conflicts of interests or loss of independence. See, for example, European Commission ([2010], p. 19) Critchley ([2008]), and Hargreaves et al. ([2003], p. 29). 
If enhanced trust is to be realized over and above basic trust, there should be further social mechanisms in place that opens up science to input from the public regarding the distribution of inductive risks. Hybrid forums properly organized, we suggested, constitute one such mechanism, which has the extra advantage of enabling people to have an informed opinion about the reliability of research under discussion. Thus, establishing them and encouraging ordinary people to participate in them can contribute to the building of enhanced trust. Promoting diversity of research groups and communities in terms of gender, ethnicity, and even nationality in some cases such as global warming, can be another way of achieving the same. Both require significant changes in the social organization of science and in science policy.

\section{Acknowledgements}

We benefited from the feedback of the audiences in Vassar College, the Eighth International Fellows Conference of the Center for the Philosophy of Science at Pittsburgh University held in Lund, Sweden, and the Istanbul Philosophy Workshop Series, where earlier versions of this paper were presented. We thank Martin Carrier, Robert Nola, Mike Thicke, Ken Waters, Kenneth R. Westphal and especially two anonymous referees of this journal for their criticisms and comments.

Gürol Irzik

Sabanci University

Tuzla, Istanbul, 35956, Turkey

irzik@sabanciuniv.edu

Faik Kurtulmus

Sabanci University

Tuzla, Istanbul, 35956, Turkey

afaikkurtulmus@sabanciuniv.edu 


\section{References}

Almassi, B. [2012]: 'Climate Change, Epistemic Trust, and Expert Trustworthiness', Ethics and Environment, 17, pp. 29-49.

Anderson, E. [2011]: 'Democracy, Public Policy, and Lay Assessments of Scientific Testimony', Episteme, 8, pp. 144-164.

Baier, A. C. [1986]: 'Trust and Anti-trust', Ethics, 96, pp. 231-260.

Baier, A. C. [1995]: 'Trust and its Vulnerabilities', in her Moral Prejudices: Essays on Ethics, Cambridge, MA: Harvard University Press, pp. 130-151.

Bignall, J. 'UK experts convinced on safety of MMR', The Lancet, 351, pp. 966.

Boyce, T. [2007]: Health, Risk and News: The MMR Vaccine and the Media, New York: Peter Lang Publishing.

Bucchi, M. [2009]: Beyond Technocracy, Dordrecht: Springer.

Chen, R. T. and DeStefano, F. [1998]: 'Vaccine Adverse Events: Causal or Coincidental?' The Lancet, 351, pp. 611-612.

Collins, H. M. and Evans, R. [2007]: Rethinking Expertise, Chicago: University of Chicago Press.

Critchley, C. R. [2008]: 'Public Opinion and Trust in Scientists: The role of the Research Context, and the Perceived Motivation of Stem Cell Researchers', Public Understanding of Science, 17, pp. 309-327.

Deer, B. [2011]: 'How the Case Against the MMR Vaccine was Fixed', The British Medical Journal, 342, pp. 77-82.

Douglas, H. [2000]: 'Inductive Risk and Values in Science', Philosophy of Science, 67, pp. 559-579.

Douglas, H. [2009]: Science, Policy, and the Value-Free Ideal, Pittsburgh: University of Pittsburgh Press.

European Commission [2010]: Science and Technology Report. Special Eurobarometer 340 / Wave 73.1-TNS Opinion and Social. <http://ec.europa.eu/public_opinion/archives/ebs/ebs_340_en.pdf>. 
Fitzpatrick, M. [2004]: $M M R$ and Autism: What Parents Need to Know, London: Routledge.

General Medical Council. [2010]: 'Dr Andrew Jeremy Wakefield: Determination on Serious Professional Misconduct (SPM) and Sanction', $<$ http://briandeer.com/solved/gmc-wakefield-sentence.pdf $>$.

Gilbert, M. [1987]: 'Modelling Collective Belief, Synthese, 73, pp. 185-204.

Goldman, A. [1986]: Epistemology and Cognition, Cambridge, MA: Harvard University Press.

Goldman, A. [2001]: 'Experts: Which Ones Should You Trust?', Philosophy and Phenomenological Research, 63, pp. 85-110.

Grasswick, H. E. [2010]: 'Scientific and Lay Communities: Earning Epistemic Trust Through Knowledge Sharing', Synthese, 177, 387-409.

Hardin, R. [2002]: Trust and Trustworthiness, New York: Russell Sage Foundation.

Hardwig, J. [1985]: 'Epistemic Dependence', The Journal of Philosophy, 82, pp. 335-349.

Hardwig, J. [1991]: 'The Role of Trust in Knowledge', The Journal of Philosophy, 88, pp. 693-708.

Hargreaves, I., Lewis, J. \& Speers, T. [2003]: Towards a Better Map: Science, the Public, and the Media. London: Economic and Social Research Council.

Holton, R. [1994]: 'Deciding to Trust, Coming to Believe', Australasian Journal of Philosophy, 72, pp. 63-76.

John, S. [2011]: 'Expert Testimony and Epistemological Free-Riding: The MMR Controversy', The Philosophical Quarterly, 61, pp. 496-517.

Jones, K. [1996]: 'Trust as an Affective Attitude', Ethics, 107, pp. 4-25.

Kitcher, P. [1993]: The Advancement of Science: Science without Legend, Objectivity without Illusions, Oxford: Oxford University Press.

Keller, E. F. [1985]: Reflections on Gender and Science. New Haven. Yale University Press. 
Longino, H. [1990]: Science as Social Knowledge. Princeton: Princeton University Press.

McCraw, B. W. [2015]: 'The Nature of Epistemic Trust', Social Epistemology, 29, pp. 413-430.

MRC [2001]: Review of Autism Research: Epidemiology and Causes, December, London: MRC.

Oreskes, N. [2007]: 'The Scientific Consensus on Climate Change: How Do We Know We're Not Wrong?' in J. F. DiMento and P. Doughman (eds), Climate Change: What It Means for Us, Our Children, and Our Grandchildren, Cambridge, MA: MIT Press, pp. 65-99.

Resnik, D. [2011]: 'Scientific Research and the Public Trust', Science and Engineering Ethics, 17, pp. 399-409.

Scheman, N. [2001]: 'Epistemology Resuscitated: Objectivity as Trustworthiness', in N. Tuana and S. Morgen (eds), Engendering Rationalities, Albany, NY: SUNY Press, pp. 23-52.

Smolkin, D. [2008]: 'Puzzles about Trust', The Southern Journal of Philosophy, 46, pp. 431-449.

Speers, T. and Lewis, J. [2004]: 'Journalists and Jabs: Media Coverage of the MMR Vaccine', Communication E Medicine, 1, pp. 171-181.

Tollefsen, D. [2007]: 'Group Testimony', Social Epistemology, 21, pp. 299311.

Uhlmann, V., Martin, C. M., Sheils, O., Pilkington, L. Silva, I., Killalea, I., Murch, S.B., Walker-Smith, J., Thomson, M., Wakefield, A.J., O'Leary, J. J. [2002]: 'Potential Viral Pathogenic Mechanism for New Variant Inflammatory Bowel Disease', Molecular Pathology, 55, pp. 84-90.

Wakefield A. J., Murch S. H., Anthony A., Linnell J., Casson D. M., Malik M., Berelowitz M., Dhillon A. P., Thomson M. A., Harvey P., Valentine A., Davies S. E., and Walker-Smith, J. A. [1998]: 'IlealLymphoid-Nodular Hyperplasia, non-Specific Colitis, and Pervasive Developmental Disorder in Children', The Lancet, 351, pp. 637-641.

Whyte K. T. and Crease R. P. [2010]: 'Trust, Expertise, and the Philosophy of Science', Synthese, 177, pp. 411-425. 
Wilholt, T. [2013]: 'Epistemic Trust in Science', British Journal For the Philosophy of Science, 64, pp. 233-53.

Wilholt, T. [2016]: 'Collaborative Research, Scientific Communities, and the Social Diffusion of Trustworthiness', in M. S. Brady and M. Fricker (eds), The Epistemic Life of Groups: Essays in the Epistemology of Collectives, Oxford: Oxford University Press, pp. 218-233. 